\title{
Perdas das frações de cana-de-açúcar submetida a diversos métodos de colheita $^{1}$
}

\author{
Ana Luiza Bachmann Schogor ${ }^{2 *}$, Luiz Gustavo Nussio ${ }^{3}$, Gerson Barreto Mourão ${ }^{3}$, Gisele \\ Bonato Muraro², Jhones Onorino Sarturi², Bruna da Conceição de Matos ${ }^{2}$
}

\author{
1 Pesquisa financiada pela FAPESP. \\ 2 Pós-graduação em Ciência Animal e Pastagens, USP/ESALQ. \\ ${ }^{3}$ Departamento de Zootecnia, USP/ESALQ.
}

RESUMO - Objetivou-se com esta pesquisa avaliar o efeito dos métodos de colheita sobre as perdas e os danos de colheita da cana-de-açúcar. As avaliações foram realizadas na variedade de cana IAC86-2480, de terceiro corte, no mês de novembro de 2006. Os métodos de colheita avaliados foram corte manual basal, corte mecanizado por meio de colhedora de forragem e corte mecanizado seguido de rebaixamento manual basal. O material colhido foi pesado e separado nas frações colmo, cana-ponta e palha. Para avaliação dos danos na touceira, foi realizada contagem do número de toletes danificados e arrancados e do número de plantas inteiras deixadas nas linhas centrais de cada parcela. O delineamento experimental foi em blocos casualizados, com três parcelas e seis repetições. A produtividade e a massa de forragem disponível foram, em média, de 80,7 e 90,3 t/ha, respectivamente. As perdas totais foram maiores no método de colheita mecanizada com rebaixamento manual, cujo valor foi de $18,5 \%$ da matéria verde colhida. Quando essas perdas foram comparadas com base na matéria seca (MS), não houve diferença entre os métodos de colheita. As perdas quantitativas e relativas das frações palha e cana-ponta foram semelhantes entre os métodos de colheita, enquanto a da fração colmo diferiu entre os métodos de colheita, gerando perdas em produtividade de matéria verde de 1,5\% para a colheita manual, 7,6\% para a colheita mecanizada e de $12,7 \%$ para a colheita mecanizada com rebaixamento manual. O número de toletes danificados e arrancados foi maior para o corte mecanizado com rebaixamento manual. O número de plantas inteiras deixadas a campo foi maior para o corte mecanizado. Como as perdas totais geradas pelo corte mecanizado com rebaixamento manual são superiores apenas em oito unidades percentuais às perdas pelo método manual e o desempenho da colheita mecanizada pode ser considerado satisfatório.

Palavras-chave: colheita manual, colheita mecânica, perdas de colheita, rebaixamento

\section{Losses in sugarcane submitted to different harvesting methods}

\begin{abstract}
The effects of harvesting methods were evaluated on losses and damage in sugarcane after harvesting. The IAC86-2480 cultivar was evaluated, in its third cut, in November, 2006. Three herbage harvesting methods were evaluated: manual cutting, mechanical cutting using a harvester and mechanical followed by manual cutting. After harvesting, the material was weighed and separated into fractions of stalks, green leaves and straw. The damage under sugarcane ratoons was evaluated by counting of the number of damaged stalks, uprooted stalks and whole plants left on the central lines of the plot. Treatments were assigned to experimental units $\left(136.5 \mathrm{~m}^{2}\right.$ ) according to a complete randomized block design, with six replications. The harvested yield and total biomass available were $80.7 \mathrm{t} / \mathrm{ha}$ and $90.3 \mathrm{t}$, respectively (average data). The total losses were higher for the mechanical followed by manual cutting as herbage harvesting method, representing $18.5 \%$ of the total harvested biomass. However, when compared on a DM basis, there were no differences among herbage harvesting methods. The quantitative and relative losses of green leaves and straw were similar among herbage harvesting methods. There was difference among herbage harvesting methods for stalk fraction, showing relative loss values of $1.5 \%$ for manual cutting, $7.6 \%$ for mechanical cutting, and $12.7 \%$ for mechanical followed by manual cutting, in relation to the harvested yield. The number of damaged and uprooted stalks was higher for mechanical followed by manual cutting as herbage harvesting method. The mechanical method significantly increased the number of plants left in the field. Due to the lower losses generated by the mechanical cutting using a harvester followed by manual cutting (up to $8 \%$ on DM basis) than the manual method, the performance of the mechanical harvesting method (with or without manual cutting after arvesting) is considered satisfactory.
\end{abstract}

Key Words: basal cutting, harvesting losses, manual harvesting, mechanical harvesting 


\section{Introdução}

A colheita de cana-de-açúcar para alimentação animal é um processo dinâmico e pode ser realizada com diversos objetivos e métodos, pois envolve o planejamento desde a época de corte até o fornecimento aos animais.

O corte manual é realizado na base da planta, por meio de podões, normalmente em propriedades de pequena demanda diária de alimento. Entretanto, o agravante desse tipo de colheita é a dificuldade de realizar os tratos culturais, uma vez que sempre haverá plantas em diversos estádios de desenvolvimento (Muraro, 2007).

Na colheita mecanizada de cana, são utilizadas máquinas colhedoras de milho e sorgo, porém, nos últimos anos, tem havido melhora no desempenho dos equipamentos utilizados em sua colheita (Balsalobre et al., 1999a; 1999b). Quando a colheita é realizada mecanicamente, a altura do corte não é rente ao solo e, dessa forma, uma porção residual do colmo permanece na base da touceira. Tradicionalmente, a recomendação técnica tem sido a eliminação do colmo remanescente, com uso de um facão, visando garantir que a rebrota do canavial seja proveniente de algumas gemas basais. Esse cuidado é importante, pois acredita-se que as plantas provenientes de gemas basais são mais produtivas e persistentes que aquelas provenientes das gemas laterais (Manzano et al., 2004).

Salvi et al. (2007) observaram que, na colheita mecanizada de cana-de-açúcar, existem algumas peculiaridades relacionadas às interações solo-planta-máquina, que resultam em perdas no campo, redução na qualidade da matériaprima e redução da longevidade do canavial. Segundo Neves et al. (2004), as perdas podem ser classificadas como visíveis e invisíveis. As perdas visíveis representam colmos inteiros e/ou suas frações, rebolos e tocos resultantes no corte basal, enquanto as invisíveis são constituídas por caldo, pequenas partículas de cana decorrentes da ação dos mecanismos rotativos que cortam, picam e limpam a cana durante o processamento interno nas máquinas.

Considerando a importância do método de colheita a ser adotado em uma propriedade, a eficiência de corte, os danos em soqueira e as perdas durante o processo, objetivou-se com este trabalho avaliar as perdas de colheita nas frações palha, folhas verdes e colmos em talhões de cana-de-açúcar submetidos aos sistemas de colheita manual, mecânico, e mecânico seguido de rebaixamento manual.

\section{Material e Métodos}

O experimento foi conduzido em área do Centro APTA Cana, no município de Ribeirão Preto, São Paulo. A classificação climática do município de Ribeirão Preto, segundo método de Köppen, é Aw, caracterizado por elevada pluviosidade, embora apresente inverno seco e verão úmido (Rolim et al., 2007). O solo da área experimental é classificado como Latossolo Vermelho Férrico, de acordo com o sistema EMBRAPA (1999).

A área experimental foi composta de seis blocos com dimensões de 9,1m × $63 \mathrm{~m}$ (573,3 m²), com três métodos de colheita nas parcelas, consideradas unidades experimentais. Cada uma das três parcelas foi composta de oito linhas de plantio, com espaçamento entre linhas de 1,30 m e 15 m de comprimento, totalizando 136,5 $\mathrm{m}^{2}$.

A variedade utilizada foi a IAC86-2480, em seu terceiro ciclo de crescimento e caracteriza-se por alto teor de sacarose, boa produtividade agrícola, longevidade de soqueira, porte ereto, baixo teor de FDN e baixa relação FDN/POL, despalha espontânea e maior rendimento de corte, resistência ao carvão e ao raquitismo da soqueira e alta exigência quanto ao ambiente de produção. Essa variedade apresenta baixo teor relativo de FDN entre as variedades produzidas e, até o ano de 2002, era cultivada por cerca de 100 mil produtores rurais em território nacional (Landell et al., 2002).

Os tratamentos foram compostos de três modalidades de colheita da planta: corte manual, corte mecanizado e corte mecanizado seguido de rebaixamento manual. O corte manual foi feito na região do colo da planta e rente ao solo, abaixo do último nó, por meio de podão. Os perfilhos resultantes desse procedimento foram manipulados cuidadosamente, evitando a remoção de estruturas da planta, e, depois de colhidos, foram organizados em feixes fora da parcela.

No caso do corte mecanizado, foi utilizada colhedora de forragem (marca Menta ${ }^{\circledR}$ modelo Colhiflex MFC 1) regulada para altura de corte de $20 \mathrm{~cm}$, tracionada por trator com potência de $88 \mathrm{cv}$, com acoplamento hidráulico e acionada pelo sistema de tomada de potência. Com os objetivos de reduzir a velocidade de deslocamento desse equipamento e evitar danos à soqueira, o trator foi provido de sistema de redução de rotação para assegurar a captação e o corte preciso dos colmos. A velocidade média de deslocamento do trator durante a colheita foi de $2,4 \mathrm{~km} /$ hora, em primeira marcha reduzida e com rotação do motor em 1.700 RPM. O conjunto de facas da colhedora foi afiado no início do corte e da colheita das parcelas de cada método de colheita. Inicialmente foram colhidas as parcelas destinadas ao corte mecanizado exclusivo e, na sequência, aquelas do corte mecanizado seguido de rebaixamento manual.

O terceiro método de corte foi o mecanizado, conforme descrito acima, e na sequência, a porção do colmo remanescente (toco) foi recepada rente ao solo, da mesma forma 
como descrito para o sistema de corte manual. O objetivo com esse método de colheita foi simular o rebaixamento do colmo remanescente após o corte mecanizado, com vistas a estimular o perfilhamento basal e a uniformidade de rebrotação, mantendo o impacto de trânsito da colhedora de forragem sobre o talhão.

Com isso, ao confrontar os métodos de colheita manual e mecânica, estabeleceu-se a possibilidade de comparação entre os sistemas de colheita (manual vs mecanizado). A comparação dos métodos de colheita mecanizado e mecanizado com rebaixamento manual permitiu avaliar o efeito do rebaixamento do colmo remanescente após a colheita mecanizada sobre as perdas de matéria-prima e os danos causados às soqueiras. E, finalmente, a comparação entre os métodos de colheita manual e mecanizado com rebaixamento manual possibilitou explorar o efeito do deslocamento da colhedora sobre o talhão.

Antecedendo a aplicação dos tratamentos (corte de uniformização), foi realizada a contagem do número total de perfilhos das seis linhas centrais de cada parcela experimental. Posteriormente, foram identificados e colhidos ao acaso 20 perfilhos adultos de cada uma das seis linhas centrais da parcela. Após a colheita, esses perfilhos foram retirados das parcelas, acondicionados em lonas plásticas para que mantivessem suas estruturas intactas e pesados em balança de campo do tipo célula de carga com precisão de $200 \mathrm{~g}$.

O número de colmos e a produtividade foram calculados por meio das equações 1 e 2 , respectivamente:

$\mathrm{N}^{\mathrm{o}}$ de colmos $/ \mathrm{ha}=(\mathrm{N} N$ $\mathrm{de}$ colmos/parcela $\times 10.000) /$ área da parcela $\left(\mathrm{m}^{2}\right)$

Produção t matéria verde/ha $=($ № de colmos/ha $\times$ peso médio do colmo (kg))/1.000)

Após a pesagem, dez perfilhos por parcela foram retirados ao acaso do montante colhido e levados ao laboratório para análise morfológica a fim de se caracterizar o perfil morfológico das plantas oriundas da área experimental em seu ciclo anterior de produção.

Do restante dos perfilhos colhidos para estimativa de produção, uma amostra adicional de plantas inteiras foi picada em unidade estacionária (marca Menta, modelo Super $20 \mathrm{~T}^{\circledR}$ ) e homogeneizada. Na sequência, as amostras foram secas em estufa de circulação forçada de ar regulada para $65^{\circ} \mathrm{C}$, por 72 horas. Assim, os valores de produtividade também foram expressos com base na matéria seca e em proporção ao conteúdo original de biomassa.

Após o corte de uniformização, foram realizadas avaliações do método de colheita e de seu efeito na touceira remanescente. Assim, foram contabilizados, nas seis linhas centrais de cada parcela, o número de toletes danificados (dilacerados ou esmagados), o número de toletes arrancados - com sistema radicular solto acima da superfície do solo e o número de plantas inteiras deixadas a campo.

Nas parcelas com o corte mecanizado, foram tomadas as medidas de altura e número de entrenós de dez tocos remanescentes, aleatoriamente ao longo de cada uma das seis linhas centrais, com o objetivo de conferir a precisão da altura de corte observada de acordo com a regulagem pretendida da altura da plataforma da colhedora.

Visando estimar as perdas de frações dos perfilhos ocasionadas por impacto mecânico decorrente do trânsito e da operação da colhedora, após o corte de uniformização, foram lançados quatro retângulos de $1 \mathrm{~m}^{2}$ em cada parcela, para coleta de material remanescente, segundo método proposto por Penati et al. (2005).

Para padronização da classificação das perdas de colheita, foi utilizada a terminologia definida por Neves et al. (2004), porém considerando somente as seguintes frações para a discussão dos dados: palha, cana ponta, toco e planta inteira.

Imediatamente após a coleta destas amostras, o material foi levado ao laboratório para separação das frações: palha, folhas verdes e colmo, que foram posteriormente quantificadas em balança com precisão de 5 g, para expressar sua participação em relação ao conteúdo original de biomassa de acordo com o tratamento imposto à parcela. Após a pesagem das frações, o material foi novamente acondicionado em sacos plásticos para posterior secagem em estufa de circulação forçada de ar regulada para $65^{\circ} \mathrm{C}$, por 72 horas, e posterior pesagem. Assim, os valores também foram apresentados com base na matéria seca em relação ao conteúdo original de biomassa. A produtividade de canade-açúcar por hectare foi calculada conforme proposto por Landell \& Silva (2004), uma vez que foram tomados valores de diâmetro e altura médios dos colmos, perfilhamento e espaçamento entre linhas.

Na análise estatística das perdas de colheita, da produtividade, da forragem disponível, em valores absolutos ou relativos, da altura do toco e do número de nós remanescentes nas touceiras, utilizou-se um modelo matemático que incluiu os efeitos fixos de bloco e de tratamento, além do efeito aleatório de resíduo, utilizando-se procedimento MIXED do programa SAS.

Nas análises das variáveis de danos da colheita (número de toletes danificados, arrancados e número de plantas inteiras deixadas por linha), utilizou-se um modelo matemático misto que incluiu o efeito fixo de tratamento, além dos efeitos aleatórios de bloco e resíduo, utilizando-se 
procedimento GLIMMIX do programa SAS, sob a metodologia dos modelos lineares generalizados considerando distribuição de Poisson, com função de ligação logarítmica de acordo com Nelder \& Wedderburn (1972). Assim, considerou-se uma correção para heterogeneidade de variâncias dos métodos de colheita.

Os melhores modelos foram identificados utilizando-se como critério a estatística de verossimilhança, além dos critérios de AIC e BIC (Littell et al., 1998). As comparações entre médias para os efeitos estudados foram realizadas por meio do teste Tukey a 5\% de probabilidade.

\section{Resultados e Discussão}

Na análise estatística das características biométricas e morfológicas (Tabela 1), constatou-se que o diâmetro e o número de plantas por metro diferiam entre as parcelas em que foi realizado o corte de uniformização, e que não houve diferenças $(P>0,05)$ entre os métodos de colheita. Assim, pode-se considerar que os métodos de colheita foram realizados em parcelas uniformes quanto ao número e diâmetro de plantas por metro, características facilitadoras de corte pela máquina forrageira, como sugerido por Balsalobre et al. (1999b).
As diferenças de até $20 \mathrm{~cm}$ na altura da planta, de até 230 g no peso de planta inteira e de até 209 g no peso do colmo não foram suficientes para ocasionar diferenças na produtividade entre os métodos de colheita (Tabela 2).

A massa de forragem disponível correspondeu à produtividade colhida somada às perdas totais (Tabela 2) e representou a quantidade de biomassa que poderia ser retirada do campo se qualquer um dos métodos de colheita fosse plenamente eficiente.

As massas de cana-de-açúcar representadas pelas produtividades colhidas variaram entre 72,5 e 88,8 t MV/ha e não diferiram entre si $(\mathrm{P}>0,05)$ em mesmo método de colheita. O mesmo comportamento foi observado para os valores de forragem disponível, que variaram entre 85,8 e 94,4 t MV/ha, e também não diferiram entre si $(\mathrm{P}>0,05)$ nos métodos de colheita testados. Os valores de produtividade foram inferiores ao reportado por Landell et al. (2002), de 94,3 t MV/ha para terceiro corte, em um ciclo de 12 meses, em situação similar. Os valores de massa de forragem disponível e de produtividade colhida (t MS/ha) não diferiram entre os métodos de colheita testados $(\mathrm{P}>0,05)$ (Tabela 3 ).

A produtividade observada no método de colheita manual foi de aproximadamente $29 \%$ de MS e, nos métodos de colheita mecanizada e mecanizada com rebaixamento

Tabela 1 - Características biométricas e morfológicas das plantas da área experimental submetida ao corte de uniformização

\begin{tabular}{lcccc}
\hline Variável & Manual & Mecanizado & Mecanizado + rebaixamento manual & Erro-padrão \\
\hline Altura, cm & $153,4 \mathrm{a}$ & $137,8 \mathrm{~b}$ & $127,4 \mathrm{c}$ & 7,41 \\
Diâmetro, cm & 2,6 & 2,5 & 2,5 & 0,04 \\
Número de nós & 19,5 & 18,8 & 18,1 & 0,80 \\
$\mathrm{~N}^{\circ}$ folhas verdes/planta & 7,7 & 7,0 & 0,1 & 0,34 \\
$\mathrm{~N}^{\circ}$ folhas senescentes/planta & 0,2 & 0,3 & 1,1 & 0,08 \\
$\mathrm{~N}^{\circ}$ folhas mortas/planta & 1,9 & 0,9 & $0,799 \mathrm{~b}$ & 0,20 \\
Peso planta inteira, kg & $1,028 \mathrm{a}$ & $0,880 \mathrm{~b}$ & 0,149 & 0,0463 \\
Peso folhas verdes/planta, kg & 0,165 & 0,163 & 0,003 & 0,0051 \\
Peso folhas senescentes/planta, kg & 0,004 & 0,003 & $0,005 \mathrm{~b}$ & 0,0013 \\
Peso folhas mortas/planta, kg & $0,013 \mathrm{a}$ & $0,005 \mathrm{~b}$ & $0,637 \mathrm{~b}$ & 0,0017 \\
Peso colmo/planta, kg & $0,846 \mathrm{a}$ & $0,709 \mathrm{~b}$ & 12,4 & 0,50 \\
Número de plantas por metro & 13,5 & 13,3 & &
\end{tabular}

Médias seguidas da mesma letra na linha não diferem entre si $(\mathrm{P}>0,05)$ pelo teste Tukey.

Tabela 2 - Produtividade, disponibilidade de forragem e perdas de colheita das frações palha, folhas verdes e colmos remanescentes

\begin{tabular}{|c|c|c|c|c|c|c|}
\hline \multirow[t]{2}{*}{ Variável } & \multicolumn{2}{|c|}{ Manual } & \multicolumn{2}{|c|}{ Mecanizado } & \multicolumn{2}{|c|}{ Mecanizado + rebaixamento manual } \\
\hline & t $\mathrm{MV} / \mathrm{ha}$ & Erro-padrão & t $\mathrm{MV} / \mathrm{ha}$ & Erro-padrão & t $\mathrm{MV} / \mathrm{ha}$ & Erro-padrão \\
\hline Forragem disponível ${ }^{1}$ & 94,4 & 4,30 & 90,9 & 4,30 & 85,8 & 4,30 \\
\hline Perdas totais & $5,6 a$ & 0,91 & $10,1 \mathrm{ab}$ & 0,91 & $13,3 b$ & 0,91 \\
\hline Palha & 3,2 & 0,20 & 2,9 & 0,20 & 2,9 & 0,20 \\
\hline Cana ponta & 1,0 & 0,15 & 0,9 & 0,15 & 1,1 & 0,15 \\
\hline
\end{tabular}

MV = matéria verde.

${ }^{1}$ Produtividade somada às perdas totais.

2 Produtividade estimada a campo.

Médias seguidas da mesma letra na linha não diferem entre si $(P>0,05)$ pelo teste Tukey. 
manual, de aproximadamente 34\% de MS (Tabelas 3 e 5). Esses valores inicialmente sugerem que diferentes proporções de partes das plantas participaram na estimativa da produtividade (em t MS/ha) e que, em decorrência da maior participação da fração colmo no método de colheita manual, essa produtividade foi considerada o primeiro indicador de que diferentes proporções das frações de perdas poderiam ser encontradas.

As perdas totais $(\mathrm{t} / \mathrm{MV})$ foram maiores $(\mathrm{P}<0,05)$ no método de colheita mecânica com rebaixamento manual, em porcentagem da matéria verde e da matéria seca (Tabelas 2 , 4 e 5, respectivamente). Contudo, conforme descrito na metodologia, esse método de colheita contabilizou as perdas das frações palha, cana-ponta e colmos, composta por tocos e plantas inteiras. No método de colheita mecânica, contabilizaram-se as perdas da fração palha, cana-ponta e colmos, compostos apenas por plantas inteiras que ficaram a campo, pois nesse caso não houve rebaixamento do toco. Com isso, as perdas totais foram semelhantes às obtidas quando realizada a colheita mecânica (com rebaixamento ou não das soqueiras), e os valores determinados pelo método de colheita mecânica com rebaixamento manual devem ser considerados os que melhor representam as perdas de colheita mecanizada de cana-de-açúcar, uma vez que a diferença entre as perdas dos métodos de colheita mecânica e colheita mecânica com rebaixamento manual somente incluiu os tocos deixados nas touceiras.

As perdas totais de colheita foram semelhantes entre os métodos de colheita se comparadas em porcentagem de MS colhida $(\mathrm{P}>0,05)$. Houve efeito do método de colheita somente sobre a fração colmo $(\mathrm{P}<0,05)$, que variou entre 1,3\% (método de colheita manual) a 11,3\% (colheita mecânica com rebaixamento manual) em relação à matéria verde colhida (Tabela 5). Esses resultados indicam que o

Tabela 3. Produtividade, disponibilidade de forragem e perdas das frações palha, folhas verdes e colmos remanescentes

\begin{tabular}{|c|c|c|c|c|c|c|}
\hline \multirow[t]{2}{*}{ Variável } & \multicolumn{2}{|c|}{ Manual } & \multicolumn{2}{|c|}{ Mecanizado } & \multicolumn{2}{|c|}{ Mecanizado + rebaixamento manual } \\
\hline & t MS/ha & Erro-padrão & t MS/ha & Erro-padrão & t MS/ha & Erro-padrão \\
\hline Forragem disponível $^{2}$ & 29,9 & 2,73 & 33,0 & 1,37 & 31,2 & 1,37 \\
\hline Perdas totais & $4,1 \mathrm{a}$ & 0,37 & $5,1 \mathrm{ab}$ & 0,37 & $6,3 b$ & 0,37 \\
\hline Palha & 2,8 & 0,17 & 2,5 & 0,17 & 2,5 & 0,17 \\
\hline Cana ponta & 0,9 & 0,14 & 0,8 & 0,14 & 1,0 & 0,14 \\
\hline
\end{tabular}

${ }^{1}$ Produtividade estimada a campo.

2 Produtividade somada às perdas totais.

Médias seguidas da mesma letra, na linha, não diferem entre si $(\mathrm{P}>0,05)$ pelo teste Tukey.

Tabela 4 - Perdas de colheita das frações palha, folhas verdes e colmos remanescentes, em porcentagem da matéria verde em relação à produtividade colhida

\begin{tabular}{lcccc}
\hline Variável & Manual & Mecanizado & Mecanizado + rebaixamento manual & \multirow{2}{*}{ Erro-padrão } \\
\cline { 2 - 4 } & \multicolumn{4}{c}{ Matéria verde } \\
\hline Perdas totais & $6,5 \mathrm{a}$ & $12,3 \mathrm{~b}$ & $18,5 \mathrm{c}$ & 1,27 \\
$\quad$ Palha & 3,7 & 3,6 & 4,0 & 0,31 \\
Cana ponta & 1,3 & 1,1 & 1,5 & 0,24 \\
Colmos & $1,5 \mathrm{c}$ & $7,6 \mathrm{~b}$ & $12,7 \mathrm{a}$ & 1,03 \\
\hline
\end{tabular}

Médias seguidas da mesma letra na linha não diferem entre si $(\mathrm{P}>0,05)$ pelo teste Tukey.

Tabela 5 - Perdas de colheita das frações palha, folhas verdes e colmos remanescentes, em porcentagem da matéria seca em relação à produtividade colhida

\begin{tabular}{|c|c|c|c|c|c|c|}
\hline \multirow[t]{2}{*}{ Variável } & \multicolumn{2}{|c|}{ Manual } & \multicolumn{2}{|c|}{ Mecanizado } & \multicolumn{2}{|c|}{ Mecanizado + rebaixamento manual } \\
\hline & $\%$ & Erro-padrão & $\%$ & Erro-padrão & $\%$ & Erro-padrão \\
\hline Perdas totais & 17,7 & 3,66 & 18,4 & 1,83 & 25,7 & 1,83 \\
\hline Palha & 13,1 & 1,75 & 9,0 & 0,87 & 10,3 & 0,87 \\
\hline Cana ponta & 3,2 & 0,90 & 2,9 & 0,45 & 4,1 & 0,45 \\
\hline Colmos & $1,3 \mathrm{a}$ & 2,23 & $6,5 \mathrm{ab}$ & 1,11 & $11,3 b$ & 1,11 \\
\hline
\end{tabular}

Médias seguidas da mesma letra na linha não diferem entre si $(P>0,05)$ pelo teste Tukey. 
método de colheita da forragem não modificou a susceptibilidade da planta em perder algumas de suas folhas verdes (fração cana ponta) e suas folhas secas (fração palha) durante o processo de colheita. De fato, as perdas em quantidade de palha e cana-ponta foram similares $(\mathrm{P}>0,05)$ entre os métodos de colheita testados (Tabelas 2 e 3 ) e as plantas perderam praticamente todas suas folhas secas durante o processo de colheita. Essa susceptibilidade da perda de palha pela variedade IAC86-2480 evidencia a característica de despalha espontânea da variedade, como reportado por Landell et al. (2002). Portanto, essas perdas não estiveram relacionadas ao método de colheita adotado no canavial e podem ser consideradas intrínsecas ao processo de colheita desta variedade de cana.

Como as perdas das frações de palha e cana-ponta foram uniformes em quantidade ou na participação relativa entre os métodos de colheita testados e, como houve variação entre os métodos de colheita somente na participação relativa à MS da fração colmo (Tabela 5), duas situações distintas foram consideradas. A primeira foi que as menores perdas durante o processo de colheita da canade-açúcar foram em torno de 6,5\% em relação à produtividade em matéria verde (Tabela 4) ou de 17,7\% em relação à produtividade de matéria seca (Tabela 5) no corte manual da cana. Por outro lado, quando observado o maior valor de perda em colmo obtido pelo método de colheita mecânica com rebaixamento manual, houve perdas de 18,5\% em relação à produtividade em matéria verde (Tabela 4) ou de 25,7\% em matéria seca (Tabela 5). Esse resultado sugere que, mesmo quando adotado o método mais eficiente de colheita (colheita manual), as perdas totais foram no mínimo de $6,5 \%$ em relação à produtividade em matéria verde (equivalente a $17,7 \%$ em relação à produtividade em matéria seca) e, quando se optou pela colheita mecânica, houve acréscimo de 12 unidades percentuais com base na matéria verde ou de 8 unidades percentuais com base na matéria seca.

O maior valor de perdas totais reportado neste trabalho foi de 13,3 t MV/ha, e 9,1 t do total são referentes à perda em colmos (tocos e plantas inteiras). Esse valor é superior ao reportado por Balsalobre et al. (1999a), que relataram perdas de até $8 \mathrm{t}$ MV/ha em tocos deixados no campo após colheita com colhedora de forragem. Muraro (2007) avaliou perdas da fração toco, simulando colheita mecanizada de cana cultivada sob espaçamentos de plantio de $0,9 \mathrm{~m}$ e 1,3 m, e um ou dois cortes por ano e encontraram perdas de toco de 11,79 a 31,27 t MV/ha. Considerando a perda da fração toco de 11,79 t/ha, referente ao espaçamento análogo de 1,3 m cortado uma vez ao ano, os valores encontrados neste estudo foram numericamente inferiores aos relatados por esses autores. Provavelmente, isso esteve relacionado ao maior potencial produtivo do canavial estudado (189,01 t MV/ha), da variedade RB72-454. Além disso, a perda da fração toco em valores relativos encontrada por esses autores representou $6,23 \%$ da produtividade, enquanto neste estudo foi de 12,7\% (Tabela 4).

Neves et al. (2004) quantificaram as perdas de massa remanescente em lavouras de cana submetidas à colheita por meio de colhedora automotriz operando sob as rotações de 1.200 rpm e 1.500 rpm do ventilador do extrator primário desse equipamento. As maiores perdas foram encontradas para a maior velocidade e foram de $5,68 \%$ para perdas totais (correspondente a perdas em rebolos, tocos, colmos, pedaços e lascas) e de 17,38\% para as perdas de massa foliar, totalizando 23,06\% da base úmida. As perdas observadas na menor velocidade foram de 2,51\% para as mesmas perdas totais e de $10,74 \%$ para perdas de massa foliar em um total de $13,25 \%$. Dentro das perdas totais, a fração toco correspondeu a somente $0,08 \%$ para 1.500 rpm e $0,14 \%$ para $1.200 \mathrm{rpm}$.

Vitti et al. (2007) comentaram que, após a colheita mecanizada de canaviais sem queima prévia (cana-crua), pode permanecer sobre o solo a massa de resíduos culturais ou palhada de 10 a $25 \mathrm{t} / \mathrm{ha}$ de material seco da cultura, pois os valores encontrados variaram de 6,5 a 9,4 t MS/ha de palhada residual. Franco et al. (2007) também observaram valor de 9,4 $\mathrm{t} \mathrm{MS} / \mathrm{ha}$ de palhada residual em um canavial submetido à colheita por meio de automotriz operando sem queima prévia.

Os valores relatados na literatura sugerem que as perdas durante a colheita com máquinas tradicionalmente utilizadas para colheita de cana com fins industriais podem ser consideradas elevadas. Neste estudo, os valores obtidos com a utilização de máquinas colhedoras de forragem foram bem inferiores (6,3 t MS/ha) (Tabela 3). Contudo, as formas de colheita geram diferentes participações das frações de perdas da matéria-prima.

A maior fração das perdas durante a colheita com colhedora automotriz correspondeu à massa foliar (MV) $\mathrm{e}$ variou de 10 a $17 \%$, enquanto, neste trabalho, as mesmas perdas foram de 1,1 a 1,5\% (Tabela 4) e estão relacionadas ao fato de que as colhedoras automotrizes dispõem de dispositivo de corte do ponteiro da cana, uma vez que esse material é considerado indesejável durante o processo de moagem realizado nas usinas de açúcar e álcool. Situação oposta ocorre quando se colhe a cana para alimentação animal, pois as folhas são desejáveis na composição da massa colhida e são bem aproveitadas como alimento.

As perdas totais em matéria verde referentes às perdas em diferentes formas do colmo na colheita realizada com colhedoras automotrizes $(5,6 \%)$ foram menores que as obtidas com colhedora de forragem (18,5\%). 
As menores perdas da fração colmo da cana-de-açúcar quando a colheita é realizada por colhedoras automotrizes se devem à maior preocupação do setor sucroalcooleiro em apresentar maior eficiência de colheita dos colmos, apresentando dispositivos que controlam a altura de corte, além de diminuir o recolhimento de impurezas na matériaprima colhida. Salvi et al. (2007) avaliaram o uso de dispositivos de controle da altura de corte automático ou controle manual da altura de corte de colhedoras automotrizes de cana e verificaram que o equipamento automático não foi eficiente em manter a altura de corte desejada. As médias encontradas por esses autores variaram entre 2,8 e 4,0 cm. Entretanto, o uso do equipamento reduziu a frequência de tocos arrancados e deixados no campo, que variou de 0,5 a $1,7 \%$. Esses autores comentaram ainda que os tocos arrancados reduziram a longevidade do canavial e, quando incorporados à matéria-prima colhida para indústria, poderiam aumentar o teor de impureza mineral.

O número de toletes danificados por linha de plantio de $15 \mathrm{~m}$ foi maior $(\mathrm{P}<0,05)$ nas áreas submetidas à colheita mecanizada com rebaixamento manual, nas quais o valor de 22,1 toletes danificados por linha de $15 \mathrm{~m}$ equivaleu a aproximadamente 1,5 tolete danificado por metro de linha de plantio (Tabela 6). Nas áreas submetidas ao corte mecanizado e ao corte manual, o número de toletes danificados por metro foi menor, e foram equivalentes a 0,8 tolete danificado por metro para a colheita mecanizada com rebaixamento manual, e 0,5 tolete danificado por metro para a colheita manual. Esses valores sugerem o efeito aditivo de dano na colheita mecanizada com rebaixamento manual, uma vez que o valor de 1,5 tolete danificado representa aproximadamente a soma algébrica de 0,8 (mecanizada) mais o dano de 0,5 tolete danificado (manual).

O número de toletes arrancados também foi maior $(\mathrm{P}<0,05)$ nas áreas submetidas ao corte mecanizado com rebaixamento manual em comparação ao corte manual, entretanto, foi considerado semelhante ao efeito do corte mecanizado. A soma algébrica dessas médias também sugere efeito aditivo no arranquio dos toletes no corte mecanizado com rebaixamento manual.
A superioridade em valores de danos apresentados, causados pelo efeito da colheita mecanizada, indica que o efeito da máquina foi mais destrutivo sobre as touceiras remanescentes e que o rebaixamento praticamente dobrou os danos causados a essas touceiras.

O número de plantas inteiras deixadas por linha de plantio foi maior $(\mathrm{P}>0,05)$ nas áreas submetidas ao corte mecanizado e não diferiu $(\mathrm{P}<0,05)$ do obtido pelo método de colheita mecanizada com rebaixamento manual. Esses valores equivaleram a afirmar que foi deixada uma planta inteira a cada $10,7 \mathrm{~m}$ para a colheita manual, uma planta a cada 1,5 m para colheita mecânica, e uma planta a cada 7,5 m para colheita mecânica seguida de rebaixamento manual. Esses dados enfatizam de outra maneira os dados de perdas da fração colmo e foram maiores para o corte mecanizado (Tabelas 5 e 6). Isso refletiu em melhor eficiência de colheita da cana quando realizado o corte manual ou o rebaixamento das soqueiras, uma vez que houve a oportunidade de retirada de parte das plantas inteiras não captadas pelo equipamento de colheita.

O valor da altura variou entre 18,5 e 22,7 cm (erropadrão $=1,05)$, e não houve diferença $(\mathrm{P}>0,05)$ entre blocos; o valor médio estimado da altura de corte foi de $20,9 \mathrm{~cm}$. O número de entrenós remanescentes no campo variou entre 1,2 e 1,8 (erro-padrão = 0,09) e não houve diferença entre blocos $(\mathrm{P}>0,05)$.

Em virtude da tomada de dados das alturas dos tocos remanescentes, do diâmetro médio dos colmos anterior ao corte e da contagem do número médio de perfilhos por metro (Tabela 6), foi possível a estimativa da produção de colmo por hectare dos tocos remanescentes contabilizados como perda, de acordo com a fórmula proposta por Landell \& Silva (2004).

Considerando os dados médios no pré-corte - 13,0 perfilhos por metro; $2,5 \mathrm{~cm}$ de diâmetro dos colmos; $20,9 \mathrm{~cm}$ de altura do toco remanescente pós corte de uniformização; e 1,3 m do espaçamento entre linhas -, o valor estimado de produção de colmo por hectare deixadas a campo foi de 10,26. Ressalta-se que, a produção de colmo por hectare estimada pelo uso da fórmula inclui somente as variáveis

Tabela 6 - Danos causados às linhas de touceiras, em número de toletes remanescentes danificados, arrancados, e número de plantas inteiras deixadas no campo em cada método de colheita utilizado

\begin{tabular}{|c|c|c|c|c|c|c|}
\hline \multirow[t]{2}{*}{ Variável } & \multicolumn{2}{|c|}{ Manual } & \multicolumn{2}{|c|}{ Mecanizado } & \multicolumn{2}{|c|}{ Mecanizado + rebaixamento manual } \\
\hline & Linha de $15 \mathrm{~m}$ & Erro-padrão & Linha de 15 m & Erro-padrão & Linha de $15 \mathrm{~m}$ & Erro-padrão \\
\hline № de toletes danificados & $6,9 c$ & 1,39 & $11,8 b$ & 1,01 & $22,1 \mathrm{a}$ & 1,04 \\
\hline № de toletes arrancados & $2,5 b$ & 0,45 & $6,7 \mathrm{ab}$ & 1,51 & $11,7 \mathrm{a}$ & 2,14 \\
\hline № de plantas deixadas & $1,4 \mathrm{~b}$ & 0,35 & $10,2 \mathrm{a}$ & 1,91 & $2,0 \mathrm{~b}$ & 1,18 \\
\hline
\end{tabular}

Médias seguidas da mesma letra, na linha, não diferem entre si $(\mathrm{P}>0,05)$ pelo teste Tukey. 
que a compõem. No método adotado para estimativa de perdas de acordo com a massa recolhida do campo após colheita, a fração colmo incluiu, além dos tocos, as plantas inteiras deixadas a campo, assim não correspondeu exatamente às mesmas estruturas.

Entretanto, o maior valor de perdas da fração colmo, de 9,1 t MV/ha, pode ser considerado semelhante à produção de colmo por hectare estimada, em decorrência do erro padrão correspondente a essa estimativa de 0,91 (Tabela 2). Em razão dos resultados obtidos, pode-se inferir que, tanto a metodologia proposta por Penati et al. (2005) como aquela indicada por Landell \& Silva (2004) podem ser utilizadas para estimativa de perdas da fração colmo para colheita mecanizada.

\section{Conclusões}

O rendimento da colheita mecanizada da cana-deaçúcar seguida ou não de rebaixamento manual dos tocos remanescentes é satisfatório, pois as perdas relativas em produtividade de matéria seca não diferem das obtidas pelos métodos de colheita manual e mecanizado com rebaixamento manual.

\section{Agradecimentos}

À Fundação de Amparo à Pesquisa do Estado de São Paulo (FAPESP), pela concessão da bolsa de estudos e pelo financiamento do projeto. À APTA-IAC, de Ribeirão Preto, São Paulo, pela disponibilização da área experimental.

\section{Literatura Citada}

BALSALOBRE, M.A.; FERNANDES, R.A.T.; SANTOS, P.M. Corte e transporte de cana-de-açúcar para consumo animal. In: SIMPÓSIO SOBRE NUTRIÇÃO DE BOVINOS, 7., 1999, Piracicaba. Anais... Piracicaba: Fundação de Estudos Agrários Luiz de Queiroz, 1999a. p.7-26.
BALSALOBRE, M.A.; SANTOS, P.M.; FERNANDES, R.A. Canade-açúcar: quando e como cortar para consumo animal. Revista Balde Branco, n.421, p.13-19, 1999b.

EMPRESA BRASILEIRA DE PESQUISA AGROPECUÁRIA EMBRAPA. Centro Nacional de Pesquisa de Solos (Rio de Janeiro, RJ). Sistema Brasileiro de Classificação de Solos. Brasília: Embrapa Produção da Informação; Rio de Janeiro: Embrapa Solos, 1999. 412p.

FRANCO, H.C.; VITTI, A.C.; FARONI, C.E. et al. Estoque de nutrientes em resíduos culturais incorporados ao solo na reforma de área com cana-de-açúcar. STAB, v.25, n.6, p.32-36, 2007.

LANDELL, M.G.A.; CAMPANA, M.P.; RODRIGUES, A.A. et al. A variedade IAC86-2480 como nova opção de cana-deaçúcar para fins forrageiros: manejo de produção e uso na alimentação animal. Campinas: Instituto Agronômico de Campinas, 2002. 36p.

LANDELL, M.G.A.; SILVA, M.A. As estratégias de seleção da cana em desenvolvimento no Brasil. Visão Agrícola, v.1, p.18-27, 2004.

LITTELL, R.C.; HENRY, P.R.; AMMERMAN, C.B. Statistical analysis of repeated measures data using SAS procedures. Journal of Animal Science, v.76, p.1216-1231, 1998.

MANZANO, R.P.; PENATI, M.A.; NUSSIO, L.G. Cana-de-açúcar na alimentação de bovinos. 2.ed. Piracicaba: Fundação de Estudos Agrários Luiz de Queiroz, 2004. 29p.

MURARO, G. Impacto do espaçamento, número de cortes e da idade de corte na produção e composição bromatológica de cana-de-açúcar para silagem. 2007. $77 \mathrm{f}$. Dissertação (Mestrado em Ciências Veterinárias) - Universidade Federal do Paraná, Curitiba, 2007.

NELDER, J.A.; WEDDERBURN, R.W.M. Generalized liner models. Journal Royal Statistical Society, v.135, n.3, p.370-384, 1972. (Series A, Part 3).

NEVES, J.L.M.; MAGALHÃES, P.S.G.; OTA, W.M. Sistema de monitoramento de perdas visíveis de cana-de-açúcar em colhedora de cana picada. Engenharia Agrícola, v.24, n.3, p.764-770, 2004

PENATI, M.A.; CORSI, M.; LIMA, C.G. et al. Número de amostras e relação dimensão:formato da moldura de amostragens para a determinação da massa de forragem de gramíneas cespitosas. Revista Brasileira de Zootecnia, v.34, n.1, p.36-43, 2005.

ROLIM, G.S.; CAMARGO, M.B.P.; LANIA, D.G. et al. Classificação climática de Köppen e de Thornthwaite e sua aplicabilidade na determinação de zonas agroclimáticas para o estado de São Paulo. Bragantia, v.66, n.4, p.711-720, 2007.

SALVI, J.V.; MATOS, M.A.; MILAN, M. Avaliação do desempenho de dispositivo de cortes de base de colhedora de cana-de-açúcar. Engenharia Agrícola, v.27, n.1, p.201-209, 2007.

VITTI, A.C.; FRANCO, H.C.J.; FARONI, C.E. et al. Balanço de massa e de nutrientes da palhada e da rebrota de cana-de-açúcar dessecada com glifosato. STAB, v.25, n.3, p.30-33, 2007. 